\title{
A look at Alibaba Double 11 Shopping Festival
}

\author{
Zhao Xingran, Song Xingni, Chen Xuanyu, Zhang Weilin, Jack, Reine De Ciel
}

During the last nine years, more and more young people are joining in the carnival on November 11 affectionately known as (Double 11 Shopping Festival). Although Chinese Millennial are often asked why they are going to do online shopping on this day by consultant groups we have never been counted in a study. Moreover, many of our peers have been left out of the dialogue. We find ourselves confused by the data that is reported. One subject that emerges is why in the age of such fabulous in store experiences do millennial chose to participate in this festival. Does our immediate peer group compare with the current marketing research consultant findings? Significantly, we are interested in what attracts this student group to the online venue from a list of motivational factors including social satisfaction and financial savings. We also surveyed student consumers readers about the particular mode of information that fuels their choice to participate in the famous shopping Carnival. In this quantitative study, we survey general modes of advertising used to make decisions about participating in the Festival. Nevertheless, we do not ask the actual names of the information sources in this study. The study provides a minor look at carnival day to analyze the data collected through different methods, such as questionnaire and search engines in the internet. The results of the evaluation show information about types of information used for Chinese millennial consumption motivation. The most interesting finding is that despite the constant depiction of the Chinese Millennial as the Luxury Splurging consumer (CITE), our immediate peer group is extremely frugal. Those surveyed state they participate for savings. This illustrates the reason why Double 11 carnival is so popular for young college students. This consumer inquiry will be used to answer some potential millennial customer satisfaction questions.

Key Words: Alibaba, Shopping Festival, Millennials, Consumption choices

Alibaba Group is a privately-owned Hangzhou-based group of Internet-based e-commerce businesses including business-to-business online web portals, online retail and payment services, a shopping search engine and data-centric cloud computing services (Alibaba Group, 2018). What's More, the company has multimedia holdings that is slated to have an enormous impact on millennial shoppers. With the Western Trade Deficit impeding sales across the Atlantic. The Giant is looking at Asian and other Eastern consumers to offload its inventory. This study may provide an initial impetus as an "elevator speech" proposal for further review.

The Double 11 Carnival refers to the highly promoted November 11th online shopping day celebrated each year. It originated from the online promotion held by Taobao Mall (Tmall) on November 11, 2009. At that time, the number of participating businesses and promotional efforts was limited, but the demand was far more than expected, consequently, November 11 became a fixed date for Tmall's large-scale promotion. Double 11 has become an annual event for the Chinese e-commerce industry and has gradually influenced the international e-commerce industry. Additionally, Double Twelve is a dual 11 promotional interactive accessory in order to once again attract consumers.

Double 11 is modeled after Black Friday. Nevertheless, there are a few differences. The first record of "Black Friday" was applied not to holiday shopping but to financial crisis: specifically, the crash of the U.S. gold market on September 24.1869. In fact, what they all have in common is a discount to attract customers to buy more goods, the difference is that Double 11 is based on Taobao or Tmall apps for online shopping in China. On Black Friday, people have to go shopping in person, and some of them even line up and sleep at shopping outlets all night to make sure they can buy what they want. Double 11 allows shoppers the option of shopping from the comfort of any location they choose in cyber space. (The Black Friday, 2018)

Chinese Millennial Consumer Mystique
As there are an estimated 450, million Chinese Millennial shoppers. This study is minuscule and provides a glimpse at the shopping experience of our modest sample of SCNU students. Wang, (2017, 2009) takes us into the Chinese Millennial Mystique calling them "Little Empresses" and "Little Emperors". The group are demographically One- Child per family policy products. The group of 19-35-year Old's are given weight as consumers in our sole literature review sources provide use with unique monikers like "complex and connected" sophisticated and savvy yet willing to spend are shared findings of research into Chinese Millennial consumers. Our goal during this short research competence training is to see were our particular group falls into this milieu.

\section{Methodology}

For primary resources, the method used was a quantitative study. We use an opinion questionnaire to directly acquire data about Alibaba's Double 11 from undergraduate students participating in the South China

Normal University (SCNU) DMU EAP Pre-session 2018. In this investigation, we use the random sampling. We invited the college students to participate, and then randomly distributed 135 questionnaires in the campus. Moreover, we invited the group to use online questionnaires to collect data. According to the survey results, we know the source of information used to make decisions about participating in the festival, as well as, how to attract students to purchase expensive high-end products which is a current problem of Alibaba. Finally, we also will be able to discuss the specific advertising portals that are favored by this group. We also used informal observation and opinion polling as a form of a panel discussion for brain storming to discuss the problems and information that we want to know and share our own views. (Business Dictionary, 2018)

For secondary resources, we used the internet to collect and analyze data. Alibaba's official website was a special resource providing the annual statistics of customer satisfaction 
for product evaluation and investigation. (LEATHERBY LIBRARIES, 2018)

\section{Results}

The primary data was collected by questionnaire. There were about 150 questionnaires distributed. Of those 150 only 107 questionnaires were completed. The online questionnaire mainly issued with my WeChat friends and Alibaba's Baidu Post Bar was most favored.

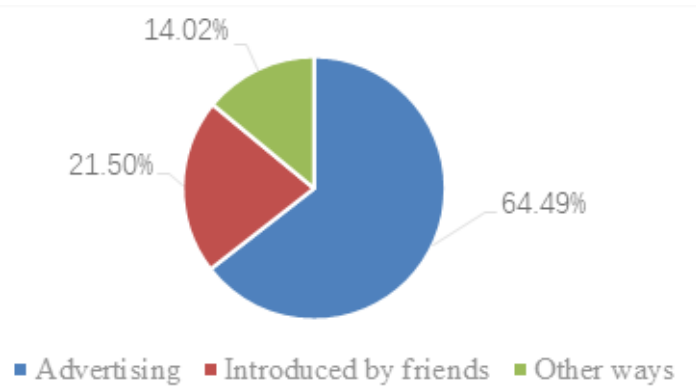

Figure 1. Shows the source of information used by millennials to make purchasing decisions.

As can be seen from the fourth question in the questionnaire. Most young people know that double 11 pairs 12 promotional activities through advertising form. The proportion of activities known through advertising accounted for $64.46 \%$ of the total. Through the introduction of friends and other means to know the dual 11 pairs of 12 activities of the people accounted for only $21.5 \%$ and $14.02 \%$ of the total proportion.

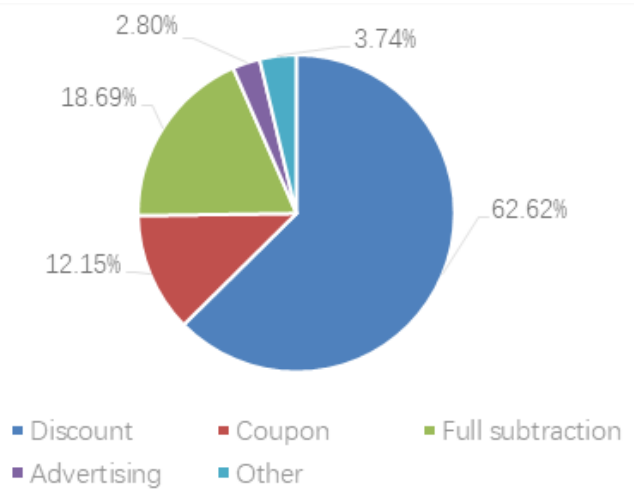

Figure 2. Deals with the motivation for participating in Double 11

From the data, we can see that the main factor attracting consumers is the discount. Its proportion has reached a staggering $62.62 \%$. This also shows that promotions are the most attractive to young consumers, discount promotions. Coupons and full reduction activities accounted for only $12.15 \%$ and $18.69 \%$ of the total. However, the present of discount in advertisement is the main factor attracting young customers. It only accounts for $2.8 \%$. Other factors accounted for $3.74 \%$ of the total ratio. The data speaks it indirect contrast investment and marketing research claims related to Chinese millennial shopping preference and habits.
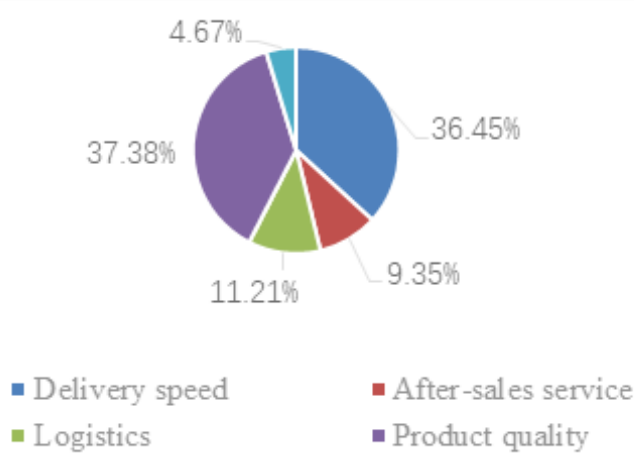

Figure 3. Deals with methods to improve the experience.

The main issue covered by this question is how consumers are dissatisfied with the Double 11 promotion. In order to improve and strengthen these issues, delivery speed and product quality are the areas that need improvement. The relatively high proportion of these two issues accounted for $36.45 \%$ and $37.38 \%$, respectively. The logistics issue cannot be ignored, it accounts for $11.21 \%$ of the total. After-sales service accounted for only $9.35 \%$ of the total proportion. The remaining $4.67 \%$ is the other negative problem.

\section{Discussion}

Situation : On this shopping festival, a large number of person go crazy to spend money shopping online, even sometimes computers crash happened. It is clear that the Alibaba Double 11 promotion is a success. The volume of transactions on the day of the Double 11 event from 2013 to 2017 has been increasing. (Alibaba, 2017)

Why do young customers participate crazy in the festival? The firstly is in the Alibaba Double 11 campaign, the promotion concept in the $4 \mathrm{ps}$ theory is mainly used. Alibaba has used the methods of discounting and full reduction to promote sales. At the same time, these two methods have attracted consumers to some extent. At 12 am on the day of the event, Taobao and other platforms began a 0 -point promotion. All products purchased at $12 \mathrm{am}$ need only $50 \%$ of the original price. This activity will greatly attract consumers to purchase goods so that such a large volume of transactions will occur.

Secondly are the referrals. According to the data from the questionnaire, there are $21.5 \%$ young people indicating that they make their purchasing decision based on introduction to discount by friends. The double 11 shopping festival is so popular among young people, consequently, this shopping festival is always mentioned by friends when they are discussing. People will also participate in this festival after they heard from friends and see the high-quality products.

Which advertisement makes the customers participate?

The first method is that Alibaba will serve ads through some traditional channels. For example, Alibaba will push ads in newspapers, magazines, subways and television. In addition, Alibaba will also conduct a large-scale promotion of the Double Eleven Shopping Festival on other channels to ensure that the shopping festival can attract enough audiences.

The second is new media marketing. with the rapid development of the Internet, more and more people are used to getting information on the Internet. Therefore, in addition to the traditional advertising methods, Alibaba also uses new 
media for advertising marketing. More specifically, Alibaba cooperates with new media such as WeChat, Weibo and various video apps, and uses these platforms to push advertising information about the Double Eleven Shopping Festival. In addition, Alibaba also encourages merchants to interact with consumers and launch a new type of multi-screen interactive mobile phone $+\mathrm{TV}+$ live broadcast, the income from the event will be returned to consumers, by allowing consumers to "see ads, grab red packets" Ways to get young consumers to participate in the Double 11 Shopping Festival in advance.

According to the data analysis, we think that Alibaba needs to investigate the transportation of products, product quality, distribution time and customer satisfaction. This activity will help the company find out where improvements need to be made. There is still some inadequacy in this shopping festival. The potential problems mainly reflected in two aspects, the first is there is a slow speed in delivery, and the second is the product quality which is difficulted to be guaranteed. During discussion it was often speculated that this is probably caused by the large numbers of products purchased on the Double 11 shopping festival.

\section{Evaluation}

The Alibaba shopping festival is relatively successful. However, there are still some problems with the Alibaba Double 11 shopping festival, such as slow logistics, poor commodity quality and phone service. According to the data analysis, here are some suggestions for Alibaba:

Improve logistics: As the logistics company directly on behalf of Alibaba customer service, the logistics service providers assessment and management is essential. For example, the choice of logistics companies should be highly competitive including a stringent bidding process, more over the contractually awarded the bid should be specialized training. Such as the distribution of the basic characteristics and requirements, including on-time delivery to help customers sign, inspection and so on. The logistics service providers assessment indicators are: punctual arrival rate, good product quality, customer service attitude.

Product quality assurance: This is a serious problem that left unchecked will inhibit the development of Alibaba. Our panel discussion found that there is a major threat of losing a large number of young users, such as our undergraduates. Therefore, Alibaba management should make product audits and resolve complaints. For example, when entering the store, the product needs to be reviewed to ensure the authenticity of the product. Customers can make a complaint to the shop, if the volume of complaints reaches a numerical threshold business are required disciplined, fined and eventually forced to close shop.

Telephone customer service: Telephone customer service is the company's understanding of customer needs the best way. However, the customer service in Alibaba has problems of poor service and after-sales service. Alibaba need to train customer service staff such as customer tone, to solve the problem of efficiency ect . Customer service staff can be satisfied with the attitude of the service evaluation. The level of satisfaction determines the fate of the customer service staff.

We believe that these solutions will benefit the double 11 shopping festival if Alibaba improves on these three aspects. Firstly, the customer needs will be better satisfied. Secondly, consumers do not have to worry about receiving expired or damaged products. Finally, the solutions will lead to great progress in Double 11 shopping festival, and Alibaba can get a better future.

\section{Conclusion}

From the analysis of data, Alibaba's Double 11 promotion is successful. However, what can't be denied is millennial consumer feel Alibaba's logistics still has some problems such as slow delivery and no guarantee of the perfection of goods quality in the process of delivery. Overall, Alibaba's Double 11 has had a lot of positive effect on people's lives. It stimulates consumption, allows young people to buy what they want at a low price on Double 11 and promotes economic communication which translates to economic growth. Contrary to popular belief young Chinese consumers are moved by deep discounts, as well as word of mouth. Referral and loyalty programs for the young may help Alibaba save money on advertisement in the future.

As far as the future is concerned, online shopping and shopping festivals like Alibaba's Double 11 can really improve people's lives. So we hope that it will become more and more perfect and will have some more positive impacts on our lives in all aspects.

\section{Reference}

Alibaba Group(2018). COMPANY OVERVIEW. (online)(cited at 8 August 2018). Available from:

URL: https://www.alibabagroup.com/en/about/overview

Alibaba Group(2017). Alibaba Group Generated US\$25.3 Billion (RMB168.2 Billion) of GMV During the 2017 11.11 Global Shopping Festival. (online)(cited at 8 August 2018). Available from: URL: http://www.alibabagroup.com/cn/news/article?news=p17 1112

Business Dictionary(2018). primary source. (online)(cited at 8 August 2018). Available from: URL:

http://www.businessdictionary.com/definition/primarysource.html

Dytchwald. Z. (2018). Chinese Millennials are about to kick US Millennials buts. New York Post. Retrieved July 29, 2018 from https://nypost.com/2018/02/17/chinese-millennials-areabout-to-kick-us-millennials-butts/

The Black Friday(2018). What is Black Friday? When is Black Friday 2018? (online)(cited at 8 August 2018). Available from:

URL: https://www.theblackfriday.com/what-is-blackfriday.shtml

LEATHERBY LIBRARIES(2018). Primary vs. Secondary Sources. (online)(cited at 8 August 2018). Available from: URL: http://www1.chapman.edu/library/instruction/tutorials/pr imary.html

Yen, D., Talkin, C. Uthayasankar, S. Luo, J et Al. (2018). Millennial Chinese consumers' perceived destination brand value. https://www.huffpost.com/entry/asian-millennials-thenew_b_12937942

Wang, Yi, Sun, M. Nan Li Sun, M and Mubayi, P, et. Al. (2015)

Wang, Wang, H. (2017). Why Chinese Millennials are "Super 
Research Article (2019)

Consumers". Forbes. retrieved July 292018 from https://www.forbes.com/sites/helenwang/2017/03/27/the- real reason-chinese-millennials-are-superconsumers/\#1fdbe57b4053 